\title{
Examining Success and Sustainability of Academic Writing: A Case Study of Two Writing-Group Models
}

Kinga Olszewska and Jennifer Lock

University of Calgary

\begin{abstract}
In contemporary higher education there is a growing demand for academics to increase their publication output. This requirement raises the question of how institutions can best support a sustainable academic writing culture, which is needed to challenge the assumption that all academics know how to write for publication. This case study examines two models used in a Faculty of Education to support writing groups for academic staff. From the analysis of reflective journals, interviews, and field notes, we identified four factors that influence the success of writing groups, as well as six conditions that support the development of sustainable academic writing. We have learned from the study that the success of a writing group is predicated on a collaborative practice that blends relational, communal, and institutional forms of sustainability in a purposeful, engaged, and reflexive way.
\end{abstract}

\section{Résumé}

Dans la sphère contemporaine des études supérieures, on demande de plus en plus aux académiciens d'être publiés. Cela soulève la question sur la façon dont s'y prennent les institutions pour soutenir efficacement une culture d'écrits académiques durables. Un tel soutien est nécessaire pour contester la présomption selon laquelle tous les académiciens savent suffisamment bien écrire pour être publiés. Cette étude de cas se penche sur deux modèles utilisés dans une Faculté de l'éducation afin de soutenir des groupes de rédaction pour le personnel universitaire. Au moyen d'analyses de revues scientifiques, d'entrevues et de notes de terrain, nous avons relevé quatre facteurs qui influencent le succès de ces groupes de rédaction. Nous avons également relevé six conditions qui soutiennent la rédaction d'écrits 
académiques durables. Cette étude nous a appris que le succès d'un groupe de rédaction est directement lié à une approche collaborative combinant des aspects relationnels, communautaires et institutionnels dans un cadre engagé, efficace et réfléchi.

\section{Introduction}

Writing groups can be an integral, if informal, part of academic development practices. The history of writing groups in academia, from student-led groups in the $18^{\text {th }}$ century to feminist writing groups in the 1980 s, indicates that writing groups are formed not only as a response to social and cultural needs but also respond to the practical needs of their participants (Ruggles Gere, 1987). The writing groups through the centuries were partly guided by a political agenda, but they also served many developmental functions in both individual and communal academic contexts. Currently, as higher educational institutions strive to advance in national and international rankings among research-intensive universities, the need for support of faculty members in their academic writing is particularly pressing.

The purpose of this paper is twofold. First, it explores writing-group models that support academics in developing their capacity to publish. Second, through a study of the two writing-group models, we examine conditions that contribute to the success and sustainability of academic writing groups. A review of the literature, along with data from participants in the study, provides a cultural context to the practice of writing groups, and identifies factors that influence their success and the conditions required to sustain them. Implications for academic writing development are examined in terms of relational, communal, and institutional forms of sustainability.

\section{Current Practices: Lessons Learned from the Literature}

One of the many misleading assumptions in academia is that all academics know how to write for publication and do it exceptionally well. The myth of inherent "writerly" knowledge is based on another assumption: that having gone through the process of writing a doctoral dissertation, a now emerging scholar has mastered all the strategies for writing articles that are publishable in peer-reviewed venues. The reality is that many academics at various stages in their careers may need some degree of support in developing academic writing skills and capacities.

The challenges faced by academics aspiring to publish are numerous. The most common are finding time for writing, difficulty with self-imposed deadlines, lack of direction and support, fear of their ideas and writing being challenged and critiqued, and fear of rejection. Confirmation of these challenges emerges not only from anecdotal evidence but also is found in literature related to academic writing (MacLeod, Steckley, \& Murray, 2012) and in practical guides written by academics for academics (Johnson \& Mullen, 2007; Silvia, 2007). While these challenges may appear to influence only emerging scholars (postdoctoral scholars and assistant professors), they are often equally true of the more seasoned academics (associate and full professors). One of the challenges that higher education institutions face is the structure of formal support of writing for academics who are often perceived as writing champions . 
The idea of an academic writing group is not novel. Yet, as academic culture changes, support for research development, particularly scholarly writing, is gaining currency. Many published studies have analyzed the factors that influence the success of writing groups or writing retreats (e.g., Aitchison \& Lee, 2006; Guerin, et.al., 2013; MacLeod et al., 2012; Page, Edwards, \& Wilson, 2012). Relatively few of these articles discuss the conditions that support a collaborative inquiry for sustainable academic writing development. Rather, the discourse focuses on practical guides for how to conduct writing groups and how the writing groups impact individual academics' performance. The discourse rarely addresses the issues of sustainability of such practice in the changing academic landscape. Also, it often does not engage the tension between the institutional requirements and the individual goals in which writing groups are situated. For example, from our review of the literature only two of publications spoke to this issue (Murray \& Newton, 2009; Kamler, 2008).

Writing groups are a social and situated practice within the context of academic identity formation, where the act of writing in a group positively influences self-assurance in emerging academics and contributes to building a research community (Aitchison \& Lee, 2006; Guerin et al., 2013; Hemmings, 2012; Lee \& Boud, 2003). Writing groups also often increase a sense of academic accountability and enable a deeper understanding of the balance between the three expectations of the academy: research, teaching, and service (Murray \& Newton, 2009; Page et al., 2012). Barbara Kamler, in examining doctoral publication practices, emphasizes the importance of formal support for writing, where writing and publication are linked to research culture and academic identity building within institutions (Kamler, 2008). As Kamler indicates, publication "flourishes when it receives serious institutional attention, and skilled support from (...) [those] who understand academic writing as complex disciplinary and identity work" (2008, p. 284).

The support offered through collaborative writing groups, can also be extended to a more intensive and focused writing practice through a writing retreat. Interestingly, writing groups and writing retreats often are not considered part of the same practice of academic writing development. A University of Strathclyde study addressed the phenomenon of a writing retreat and the impact it may have on furthering the development of a writing culture. This study analyzed the attributes of a structured writing retreat group as a process of promoting strategic engagement with writing for publication (MacLeod et al., 2012). The study used the notion of containment, which focuses on the processes that enable people to manage thoughts, experiences, and feelings, and related it to individual benefits in the context of academic writing (MacLeod et al., 2012, p. 644-645). The results showed that individual containment influenced the way in which academics deal with barriers to writing and approach their productivity. The authors found that the structured writing retreat also impacted how academics develop an understanding of writing and publication as an intrinsic part of their roles and identities as writers and academics.

Those approaches focus on emotional dimensions of academic identity formation as well as accountability through collaboration. But how do writing groups and retreats change the culture of writing over time in higher education? This may require establishing writing as a sustainable practice in individual and communal contexts. It also may need the development of leadership in cultivating a successful community of practice. 
Building a community of practice can have a role in the organizational life of a higher education institution. A community of practice built around academic writing can become part of a faculty research development strategy to fulfill its performance imperatives. But in order to achieve the performance imperatives, organizations need to build their capacity for developing, supporting, and sustaining opportunities for professional development (Wenger, 2004). As Wenger argues, "organizations have to make sure that they develop the capability to achieve their performance expectations in a sustained fashion" (p. 30). Communities of practice provide an ideal platform where such development occurs (Wenger, McDermott, \& Snyder, 2002).

There is, however, something more challenging about Wenger's model of communities of practice in performance-based higher institutions. In an academic setting, a contentious practice measures the worth of an academic by research products, including publications. As Barbara Kamler (2008) notes, publications are "the measure of quality" (2013, p. 5), and "a criterion for achieving academic promotion and competitive research funding” (2008, p. 283). Low publication records also translate into "diminished opportunities for the kinds of professional dialogue and knowledge building that can take the field forward," which influences the way we perceive the success, effectiveness, and engagement of some institutions over others (Kamler, 2008, p. 283). In this context, building a community of practice, where sharing and trust become the guiding principles, is truly challenging because the individualistic nature of writing is so tightly bound to issues of individual performance, promotion, and success. It also potentially complicates the relationship between the participants of a writing group and the group's facilitators whose work, supported by the institution, is oriented towards specific goals that align with the faculty's performance imperatives.

\section{The Context of the Study}

Given those tensions, our goal was to create a community of practice defined by peer learning, peer trust, and peer critique that supported its members in achieving their performance goals-writing for publication. We, as the writing-group facilitators, provided the initial leadership and structures to foster the creation of a community of practice in support of academic writing. We also intended to help establish writing as a sustainable practice through structured processes within a community of practice.

Within our context, there are multiple layers of success. Success is related to the consistent participation of academic staff in each iteration of the writing groups, the degree of engagement in weekly discussions, and the level of commitment to offering peer feedback. These three factors influence the success of individual academics in terms of their ability to successfully publish and to foster capacity building within the group.

Individual and group success influences sustainability. In our context, sustainability is not equivalent to longevity but rather to developing a culture that grows confidence and builds individual capacity in terms of academic writing for publication. This individual and communal capacity building has the potential over time to influence the institutional profile.

Framed by these definitions of success and sustainability, in our study, two different writing-group models supported the group's impact on community building. The models were predicated on supportive, critical, and reflexive engagement of participants who strive towards the goal of successful publication. We explore these models below. 


\section{The Writing Group}

The writing group was a joint initiative of the Office of Teaching and Learning and Office of Research to support academic writing in the Faculty of Education in a western-Canadian university. The associate dean of teaching and learning and the research facilitator conceptualized the writing group structure and dedicated time to developing the writing-group initiative. The purpose of the writing group was to provide structure, support, and allocate time to formally hone scholarly writing skills. Two key premises were used in support of this work. First, building a community of practice that would be defined by peer learning, peer trust, and peer critique was necessary if the work was to advance. Second, the facilitators would be a successful academic and a research development professional. The goal of the facilitators was to offer support to colleagues at various stages of development of their work and to foster dialogue and develop a supportive peer network within the community of practice.

The first of the two models began in fall 2013. A structured, guided process was used where faculty members and postdoctoral scholars met each week to work on their writing projects. The second, an open forum model that included a writing retreat, began in winter 2014. The rationale for using the second model was to provide an opportunity for an intense period of writing that supported the work occurring during the weekly writinggroup meetings. In both iterations we invited "writing elders": well-established and widely published senior scholars whose work is recognized as seminal in their respective areas.

\section{Model One: Structured and Guided Process}

In the structured, guided model, the writing group was built around a 12-week writing program aimed at preparing a solid draft of an article for a peer-reviewed publication at the end of the period. While offering structure and support, the program served as a model for creating a culture of collaboration across academic ranks (e.g., four postdoctoral scholars, nine professors, and a librarian) and different stages of scholarly work (e.g., drafts of articles, book chapters, and conference proposals). The group's impact on community building was predicated on supportive, critical, and reflexive engagement of participants whose goal was successful publication.

This model was built based on a challenging and structured program of writing, loosely fashioned after Belcher's (2009) Writing Your Journal Article in 12 Weeks: A Guide to Academic Publishing Success. The aim was for each participant to finalize a draft of an article for a peer-reviewed publication at the end of a 12-week period. Each week a twohour block of time was set in the calendar where participants met with the two facilitators. The first 30 to 40 minutes of the session was focused on a specific theme and the remaining time was dedicated to writing. Participation in the writing group was a gift of time that participants were giving themselves, one that allowed them to become immersed in writing during a busy day.

In order to support the peer feedback process, the group established triad peer review teams to ensure a wider variety of perspectives. Within the groups of three, each participant received feedback on their work from two colleagues, either in the meeting or via email. Following a predetermined schedule, group members were guided through the process of refining their ideas, selecting a journal, and working through each section of the paper to- 
wards a draft of an article, book chapter, or conference proposal. For example, during week two, each participant worked on refining the idea for publication and later discussed the journal of choice with the group. They examined the question, how do you make your ideas fit with the journals' direction and interests? In week four, each member brought a draft of the title and abstract for feedback and editing within the larger group. In week six, we invited a writing elder, (WE1) an established senior scholar and well-published colleague who was also a guest editor of a journal, to join the session. She shared strategies for writing and provided suggestions on how to manage and present data in writing. It was in weeks seven and onward, that members of the group began sharing drafts of their articles. The final week concluded with members reading one another's work and providing feedback.

\section{Model Two: Open Forum with Retreat}

In the open forum model, we used the same two-hour block of time for the writing group; however, initially we met every two weeks. Quickly, the group of eight academics, and a postdoctoral scholar, decided to return to weekly meetings as they felt these allowed for better organization of their time and continuation of their writing practice. The sixteen-week session began with identification of peer-review triads and personal goal setting. The peer-review process was based on timely feedback, whereby triad members requiring feedback on their work would send it via email a minimum of two days before the weekly meeting. This provided the other two members of the triad and the facilitators time to provide feedback.

As in the first iteration of the writing group, we invited a writing elder (WE2) who shared strategies and insights on finding your own voice for writing and advised group participants how to embrace the art of writing. This session was followed by a more hands-on group meeting with the writing elder who invited participants to share their work, either electronically (where it was displayed on an interactive white board screen) or in hard copy. They were then guided through an editing process.

The writing practice in this iteration of the group was extended to include a two-day writing retreat to which group members participating in both iterations of the group (fall 2013 and winter 2014) were invited. Seven people and the two facilitators participated in the writing retreat. Participation required each member to establish goals and submit a work plan before the retreat began. We requested participants link their specific projects for the writing retreat to the work they were doing during the group meetings and establish deliverables for each day of the retreat.

We began the retreat by establishing the schedule and sharing individual writing goals. During the retreat, members could work in their rooms or in common spaces; the facilitators also ensured that there was sufficient time for discussion and feedback. Towards the end of the retreat, each member reviewed the goals they initially set for the retreat. The retreat ended with each member identifying next steps in their work that would be followed up during the regular weekly writing-group time.

\section{Research Design}

A case study methodology, characterized as "particularistic" (Merriam, 1998), was used to investigate factors that influence the success of an academic writing group in our 
Faculty of Education. The study further explored conditions that support the development of a collaborative inquiry for sustainable academic development through a structured writing-group context. As noted by Merriam (1998),

[a] case study offers a means of investigating complex social units consisting of multiple variables of potential importance in understanding the phenomenon. Anchored in real-life situations, the case study results in a rich and holistic account of a phenomenon. (p. 40)

The phenomenon being studied is that of an academic writing group.

The following questions guided the inquiry:

1. What factors influence the success of academic writing groups?

2. Within a writing-group context, what conditions support the development of a collaborative inquiry for sustainable academic development?

Members of the fall 2013 and winter 2014 writing groups were invited to participate in the research. Three academic staff, two postdoctoral scholars, two writing-group facilitators, and two writing elders participated in the study. Data were collected through three sources:

1. self-reflection journalling by the two writing-group facilitators.

2. individual interviews with members of the two writing groups (fall 2013 and winter 2014) and writing elders, who were guests of the writing group (one expert per semester).

3. field notes by researchers and research assistant.

Content analysis was used for the coding of the self-reflection journal entries and the individual interviews. Field notes were assessed for themes and examples of evidence.

\section{Discussion of the Findings}

\section{Historical Foundation}

In response to the question about how successful writing groups work, the two writing elders provided some context to what we were trying to achieve through our two - models. One writing elder spoke of the historical context of writing groups by sharing two writing-group prototypes. The first, a "writing collective of people getting together and sharing drafts," emerged in the 1970s (Writing Elder 2, WE2). WE2 went on to say that this prototype focused on the process of writing and was "later taken up by the National Conference of Teachers of English, and put into freshman composition courses and then feminist writing groups all through the US" (Resolution on the National Writing Project, 1987). This elder noted that what occurred in terms of process writing from 1970 and 1980 s engaged people in "talking about, discussing, and making self-conscious the actual composing, drafting, and editing processes" (WE2). The second prototype came from the 1980 , from feminist writing groups led, for example, in Australia by Barbara Comber and Barbara Kamler. From work in the 1980 s these scholars and others participated in writing groups where the focus was on the sharing of work, being open (emotionally and professionally), engaging in the process, and letting others see a person's "text in its roughest and sometimes most grammatically and intellectually problematic forms" (WE2). 


\section{Factors that Influence Success}

Participants in the study identified four factors that influenced the success of the academic writing groups: commitment, trust, critical feedback, and structure. First, being a member of the group required commitment by allocating time for the work and meeting an expectation to engage in discussions and provide feedback. One member noted, "I feel most effective is when I have synergy with people." Allocation of time in a person's busy academic schedule was a key factor. Another member remarked, "it's more the carving out of the time that was useful." Another person commented that "just carving out the time, so making that a commitment in my schedule and actually putting it in the calendar that is a block of time where I am writing" helped her stay organized and focused. She went on to say "the accountability, so having to come back and admit it if I didn't write when I said I was going to" was a key factor in her commitment to the group and to regular writing. The commitment to meeting as a group was not seen as onerous: "It's 30 minutes per week in terms of interaction, (...) and it's a place where I can talk about my work and reflect on it." The gift of time for themselves to work on their writing was highly valued and appreciated.

Second, there was trust among the members of the writing group and making it a safe place to share their work. Both elders spoke of the need for a trusting social relationship to exist among the group members. The second writing elder commented, "It's about being aware of people involved in the group; it is a personal group, a type of consciousness raising. Sensitivity and respect will keep the negative issues out, and [encourage] regular attendance" (Writing Elder 1, WE 1). WE 2 commented, that a writing group is about "social relations, trust, and consciousness raising that comes from the feminist literature." One novice member of the group noted that she did not feel judged; rather her colleagues respected her work. She went on to say, "[the] writing group is my safest and most caring space," and members are "very supportive." Another member described the writing group as "caring, collaborative, original, inspiring, and supporti[ve]." A key component in the success of our writing group was the development of relationships and trust.

The third factor for success of the groups was the feedback from peers. Disciplinary diversity in the group allowed for various perspectives that informed members' work. One member commented that having people in other fields provided feedback and helped to ensure her writing was clear. She went on to say that if you give your writing to people in the same field they may be too close to the material and unable to provide the same kind of feedback in terms of clarity about your writing. Further, the feedback was not dependent on having work completed. Being able to share portions of the work and engage in discussion of the pieces of the work was valued. One of the academic staff members noted even a piece of work that was reviewed would be improved through the interaction and feedback from the writing group. We learned through our group meetings that for the writing group to be effective, the participants needed to be invested in the work but also invested in each other. One of the group members confirmed that, "if you are going to take time to review other people's work and give feedback, there has to be that reciprocity, where everyone is contributing and supporting each other." The strength of the writing group came from the willingness of members to engage in providing feedback and being open to receiving insights, comments, and recommendations for the purpose of enhancing the work. 
Structure, the fourth factor, was a catalyst that both supported the writing process and restricted it. One member reported that the structured approach of the writing group in the fall 2013 session helped her approach her initial writing in a fairly logical fashion. She was able to develop an outline where she began to fill in blanks in the outline. On the negative side, having a structured approach did not meet everyone's particular needs and help them through the stage they were at in the writing process. For example, one member remarked, "I was probably writing along on a piece of work when [others] were still at the beginning. ... I understand this is a big challenge because we were in a different place or [were working on a] different piece of writing." Using a structured process, also requires flexibility.

\section{Conditions to Support Sustainable Academic Development}

Within the writing-group context, six conditions that need to be in place to support the development of a collaborative inquiry for sustainable academic development were identified from the interview data. First is the creation and nurturing of a trusting community of practice, where members of that community are open to sharing with each other. As noted by one participant,

[the facilitators did a] good job of creating [an] environment where people were willing to share their work without fear of criticism. There was just enough structure and focus to make it effective but at the same time, a feeling of ease and collaboration existed.

A second condition is have a core group of people who are committed and consistently participate in the writing group. The majority of the writing group members, along with one of the writing elders, spoke of the need for consistent participation. WE 1 commented, "You can't continue to add people, it changes the whole balance." One member noted that in the fall semester there were a number of people coming and going each week. She preferred the smaller winter group, which "was not necessarily better but I think I like [it] when we have consistent participants so we get to know each other and understand one another's writing." What was beneficial for her was that people were committed to the members of the writing group and were willing to support each other's writing process. Members talked about how the commitment to regular attendance helped make people feel comfortable in sharing draft versions of their work. Another member commented, "inconsistency of participation" made it hard to "establish that collaborative spirit as effectively." What was evident was the need for a commitment to consistent participation in the writing group. Six academics have formed the core group and have since continued to participate in the initiative, along with five new members who consistently participate in each iteration of the writing group.

The third factor in developing a collaborative inquiry is the engagement of all members to sustaining the community. The facilitators brought structure to the group and created space where all members were invited to "co-design the group's goals and outline." Participants noted that the facilitators never imposed their ideas or decisions. Rather, the "collaboration [came] in their way-to-be-with us. . . . They were always asking what we need[ed] to improve our writing outcomes." The role of the facilitator in such groups 
is a deliberate balance that requires leadership and engagement rather than the need to control or even impede the organic nature of working relationships.

A fourth factor requires having two facilitators to bring alternate perspectives to the work and who help nurture the culture of trust. One participant stated: "I always like two facilitators in teaching situations because it brings two different voices and perspectives." She found that the writing-group facilitators brought "different strengths to the group, different background experiences." One facilitator was experienced in grant writing and technical writing; the other facilitator brought a perspective gained from her academic experiences, particularly her academic writing and publishing experience. The role of the facilitators was to encourage participation and the sharing of the work. From a practical perspective, if one facilitator was away the other could continue with the work so the members were not without support.

The fifth factor, flexibility and being responsive to the writing needs of the individuals must be balanced with the structure. Each person had their own writing needs and a degree of personalization was required by peers as well as the facilitators to help the writer. For example, one person noted that when she submitted her work she would ask, "Can you please give me ideas for the discussion?" and in their feedback the facilitators focused on the discussion. This participant felt that the writing group support was "always tailored" to the needs of the individual. Another person appreciated that each week one facilitator would say, "send it to me and I will give specific feedback." Facilitator feedback was also valued if a participant did not feel comfortable sending their work to everybody in the group; the facilitator would say, "send it to me and I will give you some guidance in terms of the writing." That personal support allowed individuals to gain feedback within a trusting environment in order to keep the work moving forward. Another example of responsiveness was with the role of the facilitators. One individual shared her appreciation of the facilitator's response (e.g., at the writing retreat) to her various ideas. The individual felt that each time she had a conversation with this facilitator that "she [listened] to what I [was] suggesting and [saw] where it fits with what the rest of the group and herself [needed].”

Encouraging a collaborative inquiry, the sixth factor, ensures the members and the facilitators share the responsibility for the group. One of the members spoke of how she encouraged the facilitators to share their own writing so the group could also help them to develop her writing. She explained: "I think we need to all share the responsibility and grow together because that also makes it part of the community." Further, she noted, "I think we share responsibility for continuing the work and continuing the group, not just the facilitators." If writing groups are to be sustainable, it requires various people taking on collaborative and leadership roles over time.

\section{Implications for Sustainability}

Academic writing is a public experience, where the writer's discursive capabilities and his or her intellectual capital are evaluated. The evaluative aspect of academic writing exposes the writer to personal and professional vulnerabilities, given that how much and where you publish is a measure of success and excellence. Peer critique, academic performance requirements, and institutional competitiveness play a critical role in how peer feedback, trust and collaboration are established. 
Using different writing-group models provided a learning experience for both participants and facilitators. We, the facilitators, feel that the strength of our venture lies in a model that through creation of a community of practice supports a structured and sustainable practice of a writing group, one that is responsive to the needs of the participants and to the goals of the faculty. We discovered that a structured model, one that through the gift of time and space and a weekly writing practice that culminated in the retreat, not only provided focus and accountability but also helped address faculty goals identified in the strategic plan in a concrete way. These different forms of structure contributed to the ways in which writing groups can be seen as a sustainable practice.

Through our experience with the writing group, and later the writing retreat, we discovered that there are three distinct and yet inseparable forms of sustainability that need to be understood and nurtured: relational, communal, and institutional. The success of our writing group was predicated on a collaborative practice that blended these three forms of conceptualizing sustainability in a purposeful, engaged, and reflexive way.

\section{Relational}

Our study indicated that, relational sustainability emerges from establishing trust and respect for and understanding of emotional and professional vulnerabilities. This aligns with Wenger's argument that the relationship that develops between members of the group and facilitators, if grounded in trust and combined with a critical component, establishes a strong emotional and professional bond between the group members (Wenger et al., 2002, p. 37). The relationship transforms writing from a solitary experience to a social practice. Although, the act of writing remains individual, the creative, analytical, and dialogical aspects of writing become a social process contextualized by relationships within the writing group. Writing becomes a shared practice that contributes to building sustainable professional relationships.

\section{Communal}

Responsibility, engagement, and commitment were identified in our interview data as key conditions to support sustainable academic development. Nurturing the responsible, engaged, and committed aspects of community of practice becomes one of the main factors that contribute to a writing group's communal sustainability. A key condition to establishing writing groups as a sustainable practice is the notion of shared responsibility. The responsibility relates to those aspects that create a community: (1) responsibility for the well-being of its members, (2) responsibility for ethical engagement and interaction, (3) commitment to the principles of the group, and (4) responsibility for collaborative leadership (Bauman, 1995; Levinas, 1998; Wenger, 2004). The realization and willingness to take on this responsibility by community members creates a solid foundation for sustainability of the community and its practice.

\section{Institutional}

The research suggests that institutional sustainability is perhaps the most difficult to achieve because it transcends the group's capabilities. The tension that exists between the needs for support of individual academics and the institutional requirements, and the 
competitiveness that comes with the notion of a successful leading institution seems to contradict the notion of sustainability. As WE2 explained,

So as soon as we place the writing in an institutional context it complicates matters. And certainly, in writing groups such as you've been conducting with academics, remember academics are competing for tenure. It's a narcissistic enterprise; it's a performative enterprise; it's putting your thoughts, your heart and what you are capable of on the line in front of your academic peers. That's really tough stuff.

Despite the contradiction, the institution's commitment to promote formal or informal supports for academic writing and to clearly articulate performance expectations can facilitate the growth of writing groups, thus establishing them as a sustainable practice. Examples of formal supports include dedicated time by facilitators to create a group and meeting structure to ensure there is a physical space available for members to meet. Other examples may include inviting speakers or other writing experts in order to share strategies for establishing a sustainable writing practice and overcoming challenges writing academics face. An example of an informal support is encouraging colleagues to engage in peer review of drafts of their work and providing ongoing constructive feedback. Finally, perhaps one of the most important support strategies is establishing a philosophy of collegial, collaborative practice in support of the writing practice among the group members. Such a practice helps to mitigate the competiveness among academics and create a sustainable community of practice.

\section{Conclusion}

The success of our writing group began with social relations and trust. A structured, guided process, and an open forum with a retreat model provided a means to bring people together around the common goal of scholarly writing. It was through the sharing of the work in various stages and the accompanying discourse that members developed their capacity to be writers. As noted by WE2, there are three components needed for successful writing groups to work: (1) "writing as a process"; (2) "writing as collaboration, trust, and consciousness raising"; and (3) "writing as the knowledge of the rules of the game". He also noted that the rules of the game are the ability to understand the genres, expectations of editors, and an appreciation for what the audience is looking for in the work. These three components provide a foundation for writing groups that may embrace a structured, guided process model, an open forum with retreat model, or a combination of both.

The challenge is sustainability, given that it is a significant factor in the context of writing groups. The question of sustainability comes up not only in the individual context of supporting academics in their writing processes but also in communal and institutional contexts of establishing writing as an innate part of academic practice. A practice that can be shared, learned, and taught and is one that continues to contribute to development of research and teaching capacity for the entire faculty. The idea of a successful community of practice itself cannot be divorced from the idea of making the practice of learning sustainable over time. Learning is never individual. It is always situated, contextual, and relational. Individual interactions and group and institutional dynamics are important factors in the context of professional development and learning through the work of writing groups. 


\section{References}

Aitchison, C., \& Lee, A. (2006). Research writing: Problems and pedagogies. Teaching in Higher Education, 2(3), 265-278. Retrieved from http://www.tandfonline.com/doi/ abs/10.1080/13562510600680574\#.UpTeU-LubNw

Bauman, Z. (1995). Life in fragments: Essays in postmodern morality. Oxford, UK: Wiley-Blackwell.

Belcher, W.L. (2009). Writing your journal article in 12 weeks: A guide to academic publishing success. Los Angeles, CA: SAGE.

Guerin, C., Xafis, V., Doda, D. V., Gillam, M. H., Larg, A. J., Luckner, H., \& Xu, C. (2013). Diversity in collaborative research communities: A multicultural, multidisciplinary thesis writing group in public health. Studies in Continuing Education, 35(1), 65-81.

Hemmings, B. (2012). Sources of research confidence for early career academics. Higher Education Research and Development, 31(2), 171-184.

Johnson, W. B., \& Mullen, C. A. (2007). Write to the top! How to become a prolific academic. New York, NY: Palgrave Macmillan.

Lee, A., \& Boud, D. (2003). Writing groups, change and academic identity: Research development as local practice. Studies in Higher Education, 28(2), 187-200. Retrieved from http://www.tandfonline.com/doi/abs/10.1080/0307507032000058109\#. UpTdcOLubNw

Levinas, E. (1998). Otherwise than being or beyond essence. (A. Lingis, Trans.). Pittsburgh. PA: Duquesne University Press.

Kamler, B. (2008). Rethinking doctoral publication practices: Writing from and beyond the thesis, Studies in Higher Education, 33(3), 283-294. Retrieved from http:// www.tandfonline.com/doi/pdf/10.1080/03075070802049236

Kamler, B., \& Thomson, P. (2013). Writing for peer-reviewed journals: Strategies for getting published. Abingdon, UK: Routledge.

MacLeod, I., Steckley, L., \& Murray, R. (2012). Time is not enough: Promoting strategic engagement with writing for publication. Studies in Higher Education, 37(6), 641-654.

Merriam, S.B. (1998). Qualitative research and case study applications in education: Revised and expanded from Case Study Research in Education (2nd ed.). San Francisco, CA: Jossey-Bass.

Murray, R., \& Newton, M. (2009). Writing retreat as structured intervention: Margin or mainstream? Higher Education Research \& Development, 28(5), 541-553.

National Council of Teachers of English. (1987). Resolution on the National Writing Project. Retrieved from http://www.ncte.org/positions/statements/nationalwritingproj

Page, C. S., Edwards, S., \& Wilson, J. H. (2012). Writing groups in teacher education: A method to increase scholarly productivity. SRATE Journal, 22(1), 29-35.

Ruggles Gere, A. (1987). Writing groups: History, theory and implications. Carbondale, IL: Southern Illinois University Press. 
Silvia, P. J. (2007). How to write a lot. A practical guide to productive academic writing. Washington, DC: American Psychological Association.

Wenger, E. (2004). Learning for a small planet: A research agenda. Retrieved from http://learninghistories.net/documents/learning\%2ofor\%20a\%20small\%2oplanet.pdf

Wenger, E., McDermott, R., \& Snyder, W. M. (2002). Cultivating communities of practice. Boston, MA: Harvard Business Press.

\section{Contact Information}

Kinga Olszewska, $\mathrm{PhD}$

Faculty of Arts

University of Calgary

kinga.olszewska@ucalgary.ca

Kinga Olszewska is the research facilitator in the Faculty of Arts, University of Calgary. Kinga holds a PhD in comparative literature from the National University of Ireland, Galway. She received a postdoctoral fellowship in comparative cultural studies awarded by the Irish Research Council and has a broad and eclectic understanding of the humanities and social sciences. Her extensive expertise is in research development, particularly in developing research grant proposals and providing research-development support to scholars. The guiding philosophy of her work is understanding individual approaches to research excellence and identifying factors that may influence individual academic's success.

Jennifer Lock is the associate dean in the Office of Teaching and Learning, Werklund School of Education, University of Calgary. Her four areas of research are (1) e-learning with a specific focus in distance education, online learning communities, and building capacity of online educators, (2) technology integration in education and teacher education that involves designing learning in technology-enhanced learning environments and online collaboration, (3) change and innovation in education (teaching, learning, and leading) with a specific interest in leading innovation involving educational technology, and (4) educational development and the scholarship of teaching and learning in higher education. 